J. Lake Sci. (湖泊科学) , 2015, 27(5): 829-839

DOI $10.18307 / 2015.0509$

(C) 2015 by Journal of Lake Sciences

\title{
西辽河流域鱼类生物完整性指数评价及与环境因子的关系”
}

\author{
张 浩 ${ }^{1,2}$, 丁 森 ${ }^{2 * *}$, 张 远 $^{2}$, 贾晓波 ${ }^{2}$, 孟 伟 ${ }^{2}$, 郭 彪 ${ }^{1,3}$ \\ ( 1 : 河北农业大学海洋学院,秦皇岛 066003 ) \\ (2: 中国环境科学研究院流域水生态保护技术研究室, 北京 100012) \\ (3: 天津市渤海水产研究所, 天津 300457 )
}

\begin{abstract}
摘 要: 采用鱼类生物完整性指数 (F-IBI) 评估西辽河流域环境质量,利用相关分析篮选了影响 F-IBI 的环境因子,结合 局部加权回归散点修匀法 (LOWESS) 估算了这些环境因子的保护限值. 结果表明:20 个候选参数指标中,䱊科鱼类物种 百分比、底层鱼类物种数、耐受性鱼类个体数、杂食性鱼类物种数和筑巢产卵鱼类个体百分比适合作为西辽河流域F-IBI 构建参数. 采用比值法统一参数量纲, 以参考点 F-IBI 值的 $95 \%$ 分位数作为健康参考值, 对全流域 44 个采样点进行健康 评价, 得到健康点位 5 个 $(11.4 \%)$, 亚健康点位 9 个 $(20.5 \%)$, 一般点位 12 个 (27.3\%), 差点位 11 个 $(25.0 \%)$, 极差点 位 7 个 $(15.9 \%)$. 电导率、氨氮浓度、碱度和泥沙比例与 F-IBI 呈显著负相关, 坡降和草地比例与 F-IBI 呈显著正相关. 经 LOWESS 和独立样本 $t$ 检验发现, 电导率、氨氮浓度、碱度、泥沙比例和草地比例等环境因子的保护限值分别为 $531 \mu \mathrm{S} / \mathrm{cm}$ 、 $0.55 \mathrm{mg} / \mathrm{L} 、 4.4 \mathrm{mmol} / \mathrm{L} 、 47.2 \%$ 和 $37.0 \%$, 且限值两侧的 F-IBI 分值差异显著, 该结果可作为西辽河流域环境管理中鱼类 群落完整性保护的有益参考.
\end{abstract}

关键词 : 鱼类生物完整性指数;局部加权回归散点修匀法;西辽河流域;环境因子

\section{Assessment of the fish index of biotic integrity and its relationship with environmental fac- tors in the Xiliao River Basin}

\author{
ZHANG Hao ${ }^{1,2}$, DING Sen ${ }^{2}$, ZHANG Yuan ${ }^{2}$, JIA Xiaobo ${ }^{2}$, MENG Wei ${ }^{2}$ \& GUO Biao ${ }^{1,3}$ \\ (1: Ocean College, Hebei Agricultural University, Qinhuangdao 066003, P. R. China) \\ (2: Laboratory of Riverine Ecological Conservation and Technology, Chinese Research Academy of Environmental Sciences, \\ Beijing 100012, P. R. China) \\ (3: Bohai Fisheries Research Institute of Tianjin, Tianjin 300457, P. R. China)
}

\begin{abstract}
The environmental quality of Xiliao River Basin is assessed based on the fish index of biotic integrity (F-IBI). Protection limit values of the environmental factors correlated with the F-IBI are determined by the method of locally weighted regression scatterplot smoother(LOWESS). The results indicated that five indices, including the percentage of the Cobitidae fish, the number of demersal fish species, the number of omnivorous fish species, the number of tolerated fish individuals and the percentage of the nests spawning fish individuals, were suitable for constructing the F-IBI assessment system. The ratio method is used to unify dimensionless parameters. The $95 \%$ quantile of the F-IBI in all reference sites is used as the reference value of health conditions. Forty four sampling sites of Xiliao River Basin were assessed by F-IBI. The results found that five sites $(11.4 \%)$ were in excellent grade, nine sites $(20.5 \%)$ were in good grade, twelve sites $(27.3 \%)$ were in normal grade, eleven sites $(25.0 \%)$ were in poor grade, and seven sites $(15.9 \%)$ were in very poor grade. Electrical conductivity, ammonia nitrogen, alkalinity and proportion of sand were negatively correlated with F-IBI scores in the Xiliao River Basin, whereas slope and proportion of grassland were positively correlated with F-IBI scores. The results of LOWESS and independent sample $t$ test indicated that F-IBI scores significantly changed when the electrical conductivity, ammonia nitrogen concentration, alkalinity, proportion of sand and proportion of grassland reached the protection limit value, which was $531 \mu \mathrm{S} / \mathrm{cm}, 0.55 \mathrm{mg} / \mathrm{L}, 4.4 \mathrm{mmol} / \mathrm{L}, 47.2 \%$ and $37.0 \%$, respectively.
\end{abstract}

* 国家自然科学基金项目 (41401066) 和国家水体污染控制与治理科技重大专项 (2012ZX07501-001-04) 联合资助. 2014-10-26 收稿;2015-02-05 收修改稿. 张浩(1987 ), 男, 硕士研究生; E-mail: shenduhao@ 126. com.

** 通信作者;E-mail: dingsen@ craes. org. cn. 
The results of this study could provide beneficial information for the regional environmental management of fish integrity protection in the Xiliao River Basin.

Keywords: Fish index of biotic integrity; LOWESS; Xiliao River Basin; environmental factors

水体的生物学评价对评估水体生态系统完整性和水生生物保护具有重要意义 ${ }^{[1]}$.生物完整性指数 (index of biotic integrity, IBI) 作为一种较为成熟的生物学评价方法, 已得到了广泛认可和应用 ${ }^{[2-5]}$. 关于 IBI 的 研究, 众多学者较多注重于对其研究的内容不断改进和完善, 如拓展生物类群 ${ }^{[6-8]}$ 、完善指标体系 ${ }^{[9]}$ 、构建方 法和健康评价标准 ${ }^{[0]}$ 等, 并对不同的水体类型进行健康评价, 而关于环境因子与 IBI 之间的相互关系以及 环境因子保护限值的研究鲜有报道.

我国关于生物学评价的研究多集中于地表径流连续性的水体 ${ }^{[11-15]}$. 西辽河所处区域气候干旱少雨, 多 数支流常出现季节性断流, 此外, 对西辽河流域开展的水质生物学评价研究尚不多见, 仅见高欣等 ${ }^{\left[{ }^{[1]} \text { 以大型 }\right.}$ 底栖动物为研究对象建立了本区域的水质生物评价体系. 本研究尝试构建西辽河流域鱼类生物完整性指数 ( fish index of biotic integrity, F-IBI), 了解流域内各调查样点的健康状况, 并从水化学 ${ }^{[17]}$ 、物理生境和土地利 用 ${ }^{[18]}$ 等方面篎选出对该流域 F-IBI 有重要影响的环境因子并计算其保护限值, 以期为该流域鱼类保护和环 境管理提供科学依据.

\section{1 材料与方法}

\section{1 研究区域概况}

西辽河 $\left(41.1^{\circ} \sim 45.2^{\circ} \mathrm{N}, 116.7^{\circ} \sim 124.2^{\circ} \mathrm{E}\right)$ 位于我国北方典型的农业区与牧业区交汇过渡地带, 流域 面积约为 $20.1 \times 10^{4} \mathrm{~km}^{2[19]}$, 其干流长为 $827 \mathrm{~km}$, 流域内大的支流有西拉木伦河、老哈河、教来河等. 该流域 的主要气候特征为干旱少雨, 其水分年蒸发量远大于补给量, 水土流失和草场荒漠化严重, 区域内大部分河 流处于全年断流或季节性断流状态. 该区域的环境压力主要来自自身和人类干扰.

\section{2 调查方法}

2012 年 8 月在西辽河流域设置 44 个调查断面 (图 1). 对于可涉水河流使用电鱼法进行样本调查, 对于

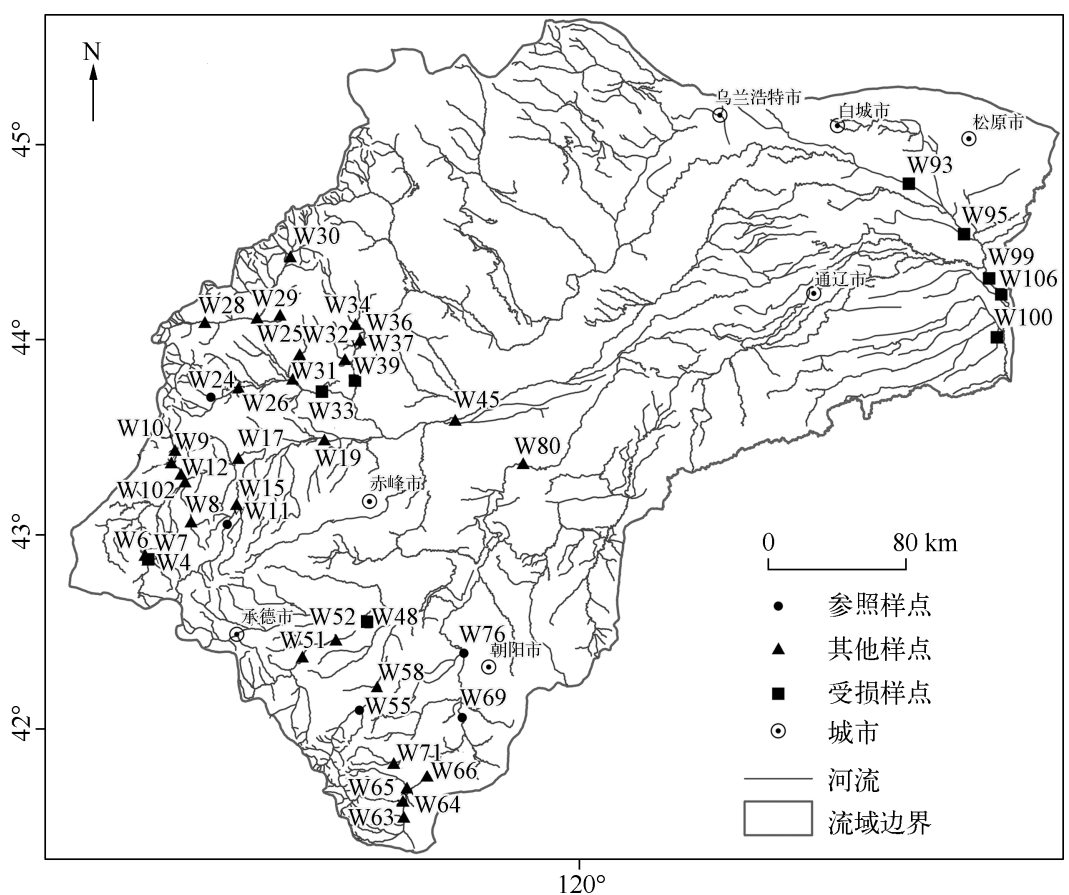

图 1 西辽河流域调查点位分布

Fig. 1 Distribution of the sampling sites in the Xiliao River Basin 
不可涉水河流采用刺网采样 (孔径大小为 $5 \mathrm{~cm}$ ) 和电鱼法相结合的调查方法, 每个断面的调查距离约为 $300 \mathrm{~m}$,调查时间为 $30 \mathrm{~min}$. 对采集的鱼类进行物种鉴定和生物学测量,并最终放归河流.

环境因子调查主要涉及水化、物理生境和土地利用 3 方面内容. 水化指标包括水温、溶解氧 ( DO ) 、 $\mathrm{pH}$ 、 电导率 (Cond)、浊度 ( Tur)、悬浮物 $(\mathrm{SS})$ 、氨氮 $\left(\mathrm{NH}_{3}-\mathrm{N}\right)$ 、硬度 $(\mathrm{THD}) 、$ 碱度 $(\mathrm{Alk}) 、$ 硝酸盐 $\left(\mathrm{NO}_{3}^{-}\right)$、总氮 $(\mathrm{TN})$ 、磷酸盐 $\left(\mathrm{PO}_{4}^{3-}\right)$ 、总磷 $(\mathrm{TP})$ 和高锰酸盐指数 $\left(\mathrm{COD}_{\mathrm{Mn}}\right)$ 等. 水温、DO、 $\mathrm{pH}$ 和 Cond 采用 YSI Pro2030 多参 数水质分析仪现场测定, Tur 采用 HACH 2100 Q 浊度仪现场测定, 其它水质参数参考相关国家标准在实验室 进行测定. 水样采集、保存及测定参照《水和废水监测分析方法》(第4 版 $)^{[20]}$.

物理生境特征指标包括坡降、蜿蜒度和底质粒径 (巨砾、鹅卵石、小卵石、砂砾和泥沙的比例); 其中坡降 和蜿蜒度用 ArcGIS 9.3 软件进行分析, 底质粒径组成用笁网进行现场分析, 并将粒径大于 $128 \mathrm{~mm}$ 的定义为 巨砾, 粒径为 $64 \sim 128 \mathrm{~mm}$ 的定义为鹅卵石, 粒径为 $16 \sim 64 \mathrm{~mm}$ 的定义为小卵石, 粒径为 $4 \sim 16 \mathrm{~mm}$ 的定义为 砂砾,粒径小于 $4 \mathrm{~mm}$ 的定义为泥沙.

土地利用方式包括未利用地、水域、林地、建设用地、耕地和草地等. 本研究分析了调查样点河岸带两侧 各 $3 \mathrm{~km}$ 和样点上、下游各 $3 \mathrm{~km}$ 范围内的土地利用情况,该数据使用 ArcGIS 9.3 软件分析获得.

\section{3 数据处理}

1.3.1 F-IBI 评价计算 该过程包括 4 个基本步骤: (1) 参照点位的篮选. 参照渠晓东等的标准化方法 ${ }^{[10]}$ 进 行参考点位的篮选, 即根据《地表水环境质量标准》(GB 3838-2002) 和生境评分结果对采样点进行评价: 样 点水质为 II 类及以上,生境评分为 140 分及以上, 同时人类活动强度与河岸土地利用类型两项指标得分 $(\geqslant 30)$ 均较高的为参照点; 水质为 $\mathrm{V}$ 类及劣 $\mathrm{V}$ 类,生境评分为 120 分以下, 同时人类活动强度与河岸土地利 用类型两项指标得分 $(<25)$ 均较低的采样点为受损点. (2) IBI 指标体系的构建. 综合参考目前鱼类 IBI 的 相关研究报道 ${ }^{[12,15,21-23]}$, 并结合本次鱼类调查的实际情况, 从 5 个方面进行评价体系构建: 物种组成与丰度、 耐受性和敏感性、营养结构、鱼类数量与健康状况、繁殖共位体. 从上述 5 个方面共选取对环境变化较为敏 感的 20 个指标作为评价体系的候选指标 (表 1). (3) 指标的篮选. 参考当前 IBI 计算中的指标笁选方 法 ${ }^{[21-22]}$, 对上述指标依次进行分布范围篮选、判别能力分析、相关性计算等. 最终选取适合作为该区域 F-IBI 的构建指标. 其中分布范围篮选是指候选指标在超过 5\% 以上样点得分不为 0 , 否则放弃该评价指标 ${ }^{[21]}$; 判 别能力分析是指对参考点和受损点在 $25 \%$ 75\% 分位数分布范围 (即箱体 $I Q$ 值) 重叠情况的比较, 若箱体没 有重叠, 则 $I Q$ 值为 3 , 若箱体部分重叠, 但是彼此的中位值均不在对方箱体内, 则 $I Q$ 值为 2 , 若箱体重叠且一 者中位值在对方箱体内, 则 $I Q$ 值为 1 , 若箱体重叠且彼此中位值均在对方箱体内, 则 $I Q$ 值为 0 , 在研究中仅 对 $I Q$ 值 $\geqslant 2$ 的情况做进一步分析 ${ }^{[22]}$; 相关性计算指对通过判别能力分析的各候选指标进行 Pearson 相关性 分析, 对于 $|R|>0.9$ 的指标仅选其一 ${ }^{[22]}$. (4) 西辽河 F-IBI 的健康评价. 对各构建指标按比值法进行量纲统

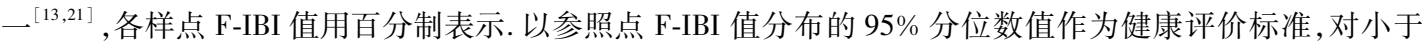
95\% 分位数值的分布范围进行 4 等分, 分别划分出亚健康、一般、差和极差的评价标准.

1.3.2 环境因子保护限值计算 环境变量同 F-IBI 进行 Spearman 相关性分析, 对具有显著相关性的环境变 量, 利用局部加权回归散点修匀法 (locally weighted regression scatterplot smoother, LOWESS) 进行拟合, 在曲 线最为平滑的情况下 $(f=0.9)$, 将曲线明显转折处作为环境变量对 F-IBI 的保护限值 ${ }^{[23]}$, 并利用独立样本 $t$ 检验法,对各环境因子的保护限值进行检验.

环境和鱼类状况等基础性分析采用 Excel 2007 软件完成,参考点与受损点箱体图绘制采用 Oringin 8.5 软件完成,环境因子保护限值分析和环境因子间相关性分析图采用 R 3.03 语言分析软件完成,相关性分析 和独立样本 $t$ 检验采用 SPSS 19.0 软件完成.

\section{2 结果}

\section{1 鱼类组成和环境特征}

本次调查共采集到鱼类样本 9899 尾,隶属于 5 目 8 科 25 属 28 种. 其中,鲤形目鱼类最多,有 20 种; 鲈 形目其次,有 4 种; 鲇形目较少,有 2 种; 刺鱼目和鲟形目最少,分别只有 1 种. 鲇、黄颡鱼、鲤、宽鳍鱲和大鳞 副泥鲉等物种在该流域内分布较少; 北方条鳅、达里湖高原鱾、棒花鱼、洛氏鱥、鲫和麦穗鱼等物种数量较 
多; 鲫、棒花鱼、麦穗鱼、北方条鳅和泥鳅等物种分布较广. 通过参考相关文献 ${ }^{[9,12,24]}$ 和实际调查经验, 对该流 域各鱼类相关生态信息进行总结(表 2).

表 1 西辽河流域鱼类 IBI 候选指标列表

Tab. 1 List of F-IBI candidate metrics for Xiliao River Basin

\begin{tabular}{|c|c|c|c|c|}
\hline 指标种类 & 候选参数指标 & 对干扰的响应 & 分布范围 & 参数缩写 \\
\hline \multirow[t]{8}{*}{ 物种组成与丰度 } & 鲤科鱼类物种百分比 & 上升 & $0 \sim 1$ & M1 \\
\hline & 鱾科鱼类物种百分比 & 下降 & $0 \sim 1$ & M2 \\
\hline & 鰕虎鱼科鱼类物种百分比 & 下降 & $0 \sim 0.17$ & M3 \\
\hline & 刺鱼科鱼类物种百分比 & 下降 & $0 \sim 0.25$ & M4 \\
\hline & 青鮡科鱼类物种百分比 & 下降 & $0 \sim 0.14$ & M5 \\
\hline & 中上层鱼类物种数 & 下降 & $0 \sim 2$ & M6 \\
\hline & 底层鱼类物种数 & 上升 & $0 \sim 7$ & M7 \\
\hline & 本地特有种所占比例 & 下降 & $0 \sim 1$ & M8 \\
\hline \multirow[t]{2}{*}{ 耐受性和敏感性 } & 敏感性鱼类个体数 & 下降 & $0 \sim 323$ & M9 \\
\hline & 耐受性鱼类个体数 & 上升 & $0 \sim 249$ & M10 \\
\hline \multirow[t]{3}{*}{ 营养结构 } & 杂食性鱼类物种数 & 上升 & $1 \sim 11$ & M11 \\
\hline & 植食性鱼类物种数 & 下降 & $0 \sim 1$ & M12 \\
\hline & 昆虫食性鱼类物种数 & 下降 & $0 \sim 3$ & M13 \\
\hline \multirow[t]{3}{*}{ 鱼类数量与健康状况 } & 总个体数 & 下降 & $1 \sim 624$ & M14 \\
\hline & 患病个体百分比 & 上升 & $0 \sim 0.03$ & M15 \\
\hline & 渔获量 & 下降 & $0.3 \sim 2081.4$ & M16 \\
\hline \multirow[t]{4}{*}{ 繁殖共位体 } & 浮性卵鱼类个体百分比 & 下降 & $0 \sim 0.14$ & M17 \\
\hline & 沉性卵鱼类个体百分比 & 下降 & $0 \sim 0.1$ & M18 \\
\hline & 筑巢产卵鱼类个体百分比 & 上升 & $0 \sim 1$ & M19 \\
\hline & 特殊产卵鱼类个体百分比 & 下降 & $0 \sim 0.44$ & M20 \\
\hline
\end{tabular}

对西辽河流域 44 个调查断面的 27 个水化学和物理生境等环境因子的整体状况进行分析统计. 在水化学 方面,参照国家《地表水环境质量标准》( GB 3838-2002), 表明水温、DO 和 $\mathrm{pH}$ 均在合理范围内, $\mathrm{COD}_{\mathrm{Mn}}$ 、 $\mathrm{NH}_{3}-\mathrm{N} 、 \mathrm{TN}$ 和 TP 浓度等水质评价所选变量的最大值均已达到劣 $\mathrm{V}$ 类; 物理生境方面, 各环境因子变化幅度均 较大 (表 3 ).

\section{2 F-IBI 评价}

2. 2. 1 参考点位选择 按照上述点位笁选方法, 最终笁选出了 W11、W24、W55、W69 和 W76 共计 5 个点位为 参照点; W6、W33、W39、W48、W93、W95、W99、W100 和 W106 共计 9 个点位为受损点.

2.2 .2 指标篎选 各候选指标都通过了分布范围的篎选. 在候选指标判别能力的笁选中, M2、M7、M10、M11 和 M19, 共计 5 个指标在参照点和受损点间有显著差异 $(P<0.05)$, 其中 M2、M11 和 M19 的 $I Q$ 值为 $3, M 7$ 和 M10 的 $I Q$ 值为 2(图 2). 对上述 5 个指标进行 Pearson 相关性检验 (表 4 ), 所有 $|r|$ 值均小于 0.9 , 最终确 定 5 个指标作为构建西辽河流域 IBI 评价的参数指标.

2. 2.3 评分及评价 根据笁选出的构建西辽河流域 IBI 的各参数指标 (表 5 ) 及各自对干扰的反应, 计算出各 参数指标在样点的得分及 IBI 值, 并确定西辽河流域鱼类生物完整性评价标准(表 6).

2.2.4 评价结果 根据该流域 F-IBI 的健康评价标准, 对全流域样点进行健康评价, 结果发现健康点位 5 个, 亚健康点位 9 个, 一般点位 12 个, 差点位 11 个, 极差点位 7 个, 其各自在全流域所占比例依次为 $11.4 \% 、 20.5 \% 、 27.3 \% 、 25.0 \%$ 和 $15.9 \%$. 健康和亚健康点位主要集中在河流源头区的中上游, 较差 和极差的点位主要分布在河流的下游区域 (图 3 ); 同时, 河流健康状况与其所处区域开发状况密切 相关. 
表 2 西辽河流域鱼类组成

Tab. 2 Fish species composition of the Xiliao River Basin

\begin{tabular}{|c|c|c|c|c|c|c|c|c|}
\hline 目 & 科 & 种 & 尾数 & $\begin{array}{c}\text { 全长范围/ } \\
\mathrm{mm}\end{array}$ & 生活水层 & 耐受性 & 食性 & 繁殖类型 \\
\hline \multirow[t]{20}{*}{ 鲤形目 } & 鲤科 & 鲫 Carassius auratus & 813 & $26 \sim 636$ & 中下层 & 耐污 & 杂食性 & 黍性卵 \\
\hline & & 鲤 Cyprinius carpio & 5 & $36 \sim 44$ & 中下层 & 耐污 & 杂食性 & 黍性卵 \\
\hline & & 粲 Hemiculter leucisculus & 17 & $48 \sim 133$ & 中上层 & 耐污 & 杂食性 & 浮性卵 \\
\hline & & 洛氏鱥 Phoxinus lagowskii & 931 & $22 \sim 167$ & 中下层 & 敏感 & 杂食性 & 黍性卵 \\
\hline & & 马口鱼 Opsariichthys bidens & 150 & $54 \sim 162$ & 中上层 & 敏感 & 肉食性 & 黏性卵 \\
\hline & & 兴凯鱊 Acheilognathus chankaensis & 138 & $24 \sim 98$ & 中下层 & 耐污 & 植食性 & 特殊产卵 \\
\hline & & 棒花鱼 Abbottina rivularis & 955 & $29 \sim 103$ & 中下层 & 耐污 & 杂食性 & 筑巢产卵 \\
\hline & & 棒花鮈 Gobio rivuloides & 408 & $31 \sim 135$ & 中下层 & - & 杂食性 & - \\
\hline & & 高体鮈 G. soldatovi & 58 & $33 \sim 81$ & 底层 & - & 昆虫食性 & 黏性卵 \\
\hline & & 清徐胡鮈 Huigobio chinssuensis & 18 & $35 \sim 66$ & 中下层 & 中等耐污 & 杂食性 & - \\
\hline & & 麦穗鱼 Pseudorasbora Parva & 631 & $26 \sim 90$ & 中下层 & 极度耐污 & 杂食性 & 黏性卵 \\
\hline & & 宽鳍鱲 Zacco platypus & 1 & $<20$ & 中上层 & 耐污 & 杂食性 & 沉性卵 \\
\hline & & 东北雅罗鱼 Leuciscus waleckii & 47 & $52 \sim 125$ & 中上层 & - & 杂食性 & 黍性卵 \\
\hline & & 彩石鳑鲏 Rhodeus lighti & 50 & $33 \sim 50$ & 中下层 & 极度敏感 & 杂食性 & 特殊产卵 \\
\hline & 鳅科 & 北方条鲀 Nemachilus nudus & 2925 & $32 \sim 136$ & 底层 & - & 杂食性 & 黏性卵 \\
\hline & & 北方花鳅 Cobitis granoei & 115 & $35 \sim 116$ & 底层 & 中等耐污 & 植食性 & 黍性卵 \\
\hline & & 泥鲀 Misgurnus anguillicaudatus & 94 & $44 \sim 172$ & 底层 & 耐污 & 杂食性 & 黍性卵 \\
\hline & & 纵纹北鱾 Lefua costata & 176 & $27 \sim 82$ & 底层 & - & 杂食性 & 黏性卵 \\
\hline & & 达里湖高原鳅 Triplophysa dalaica & 1743 & $32 \sim 535$ & 底层 & 中等耐污 & 杂食性 & - \\
\hline & & 大鳞副泥鳅 Paramisgurrnus dabryanus & 2 & $53 \sim 128$ & 底层 & 中等耐污 & 杂食性 & 沉性卵 \\
\hline \multirow[t]{2}{*}{ 鲇形目 } & 鲇科 & 鲇 Silurus asotus & 3 & $218 \sim 287$ & 底层 & 中等耐污 & 肉食性 & 黍性卵 \\
\hline & 魭科 & 黄颡鱼 Pelteobagrus fulvidraco & 1 & $<20$ & 底层 & 耐污 & 肉食性 & 筑巢产卵 \\
\hline \multirow[t]{4}{*}{ 鲈形目 } & 鰕虎鱼科 & 子陵吻鰕虎鱼 Ctenogobius giurinus & 13 & $26 \sim 53$ & 底层 & 耐污 & 昆虫食性 & 黍性卵 \\
\hline & & 褐吻鰕虎鱼 Rhinogobius brunneus & 5 & $29 \sim 53$ & 底层 & 耐污 & 杂食性 & 黍性卵 \\
\hline & & 波氏吻鰕虎鱼 $R$. cliffordpopei & 185 & $22 \sim 51$ & 底层 & 耐污 & 杂食性 & 黏性卵 \\
\hline & 塘鳢科 & 黄䱂 Hypseleotris swinhonis & 55 & $22 \sim 51$ & 底层 & 中等耐污 & 昆虫食性 & 黍性卵 \\
\hline 刺鱼目 & 刺鱼科 & 中华多刺鱼 Pungitius sinensis & 279 & $26 \sim 67$ & 中下层 & 敏感 & 昆虫食性 & 筑巢产卵 \\
\hline 鲟形目 & 青鲟科 & 青鳉 Oryzias latipes & 81 & $23 \sim 41$ & 中上层 & 中等耐污 & 昆虫食性 & 浮性卵 \\
\hline
\end{tabular}

一表示信息不详.

表 3 西辽河流域环境特征

Tab. 3 Environmental characteristics of the Xiliao River Basin

\begin{tabular}{cccccc}
\hline 环境因子 & 数值范围 & 环境因子 & 数值范围 & 环境因子 & 数值范围 \\
\hline 水温 $/{ }^{\circ} \mathrm{C}$ & $10.8 \sim 27.3$ & $\mathrm{PO}_{4}^{3-} /(\mathrm{mg} / \mathrm{L})$ & $0 \sim 0.52$ & 小卵石比例 $/ \%$ & $0 \sim 63$ \\
$\mathrm{DO} /(\mathrm{mg} / \mathrm{L})$ & $4.32 \sim 11.11$ & $\mathrm{TP} /(\mathrm{mg} / \mathrm{L})$ & $0.01 \sim 0.56$ & 砂砾比例 $/ \%$ & $0 \sim 50$ \\
$\mathrm{pH}$ & $7.30 \sim 9.12$ & $\mathrm{THD} /(\mathrm{mg} / \mathrm{L})$ & $95.44 \sim 341.68$ & 泥沙比例 $/ \%$ & $0 \sim 100$ \\
$\mathrm{Cond} /(\mu \mathrm{S} / \mathrm{cm})$ & $140.8 \sim 885.0$ & $\mathrm{Alk} /(\mathrm{mmol} / \mathrm{L})$ & $1.14 \sim 7.15$ & 未利用地比例 $/ \%$ & $0 \sim 47$ \\
$\mathrm{Tur} / \mathrm{NTU}$ & $4.03 \sim 4883.33$ & $\mathrm{COD}_{\mathrm{Mn}} /(\mathrm{mg} / \mathrm{L})$ & $1.36 \sim 32.30$ & 水域比例 $/ \%$ & $0 \sim 29$ \\
$\mathrm{SS} /(\mathrm{mg} / \mathrm{L})$ & $39.75 \sim 4622.00$ & 坡降 $/ \%$ & $0.11 \sim 19.66$ & 林地比例 $/ \%$ & $0 \sim 48$ \\
$\mathrm{NH}_{3}-\mathrm{N} /(\mathrm{mg} / \mathrm{L})$ & $0.06 \sim 4.27$ & 蜿蜒度 $/ \%$ & $1.01 \sim 1.47$ & 建设用地比例 $/ \%$ & $0 \sim 29$ \\
$\mathrm{NO}_{3}^{-} /(\mathrm{mg} / \mathrm{L})$ & $0.01 \sim 0.84$ & 巨砾比例 $/ \%$ & $0 \sim 72$ & 耕地比例 $/ \%$ & $0 \sim 84$ \\
$\mathrm{TN} /(\mathrm{mg} / \mathrm{L})$ & $0.27 \sim 7.11$ & 我鸟卵石比例 $/ \%$ & $0 \sim 60$ & 草地比例 $/ \%$ & $0 \sim 84$ \\
\hline
\end{tabular}



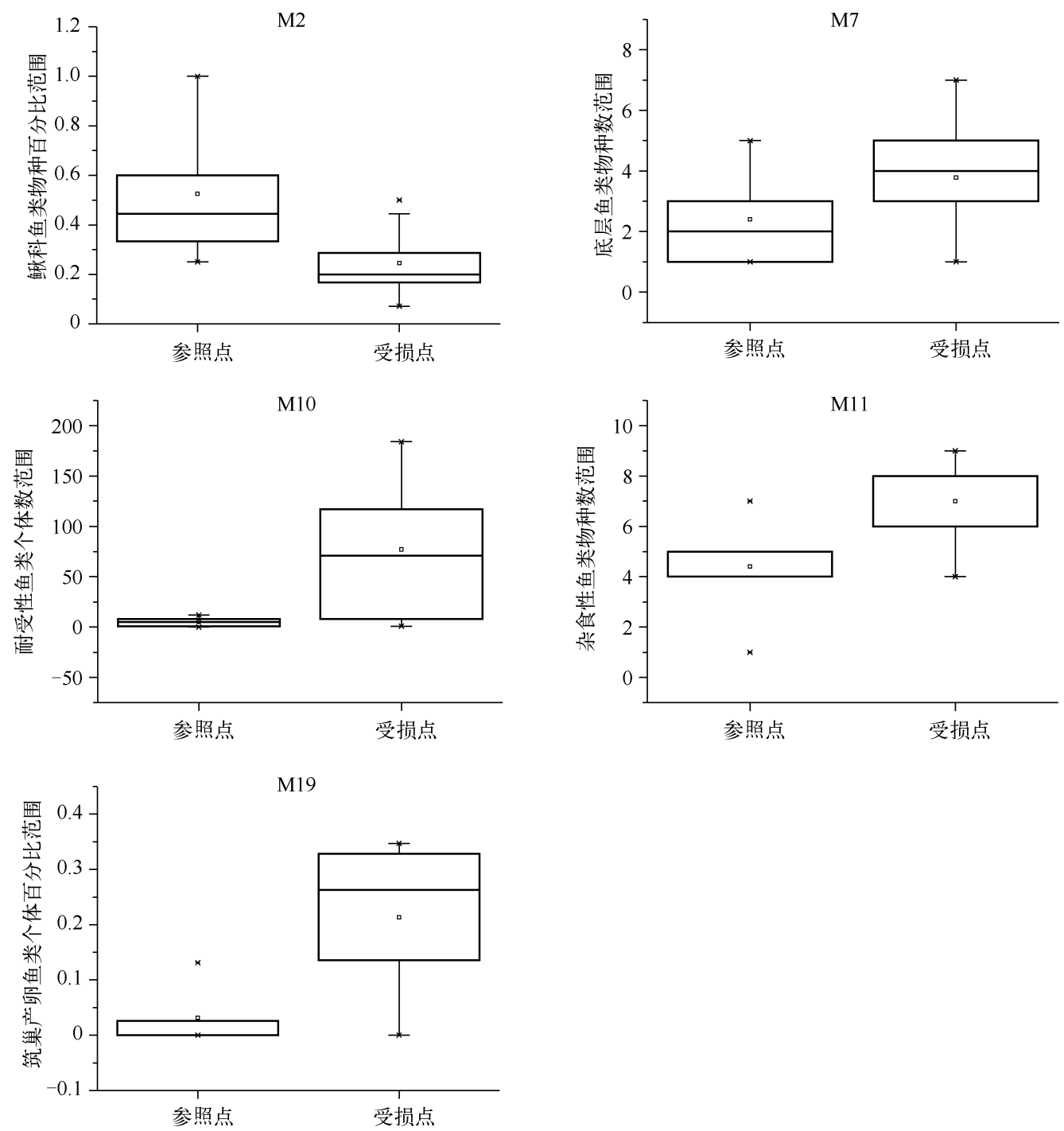

图 2 通过判别能力笁选的 5 个候选指标在参照点和受损点的箱体图

Fig. 2 Box-plots of 5 candidate metrics which accepted by the discriminatory power analysis between reference sites and impaired sites

\section{表 45 个候选指标的 Pearson 相关性计算}

Tab. 4 The pearson correlation coefficient among 5 candidate biological metrics

\begin{tabular}{cccccc}
\hline 候选指标 & M2 & M7 & M10 & M11 & M19 \\
\hline M2 & 1 & & & & \\
M7 & -0.45 & 1 & 1 & 1 & 1 \\
M10 & -0.43 & 0.66 & 0.42 & 0.77 & \\
M11 & -0.34 & 0.55 & 0.50 & & \\
M19 & -0.62 & 0.57 & & & \\
\hline
\end{tabular}


表 5 F-IBI 构建参数

Tab. 5 Biological metrics of F-IBI

\begin{tabular}{llccccc}
\hline 指标种类 & 指标名称 & 指标缩写 & 最大值 & 最小值 & $95 \%$ 分位数 & $5 \%$ 分位数 \\
\hline 物种组成与丰度 & 䱊科鱼类物种百分比 & M2 & 1.00 & 0 & 1.00 & 0.14 \\
& 底层鱼类物种数 & M7 & 7 & 0 & 5.00 & 1.00 \\
耐受性 & 耐受性鱼类个体数 & M10 & 249 & 0 & 180.80 & 0 \\
营养结构 & 杂食性鱼类物种数 & M11 & 11 & 1 & 8.85 & 1.00 \\
繁殖共位体 & 筑巢产卯鱼类个体百分比 & M19 & 0.43 & 0 & 0.36 & 0 \\
\hline
\end{tabular}

表 6 西辽河流域鱼类生物完整性评价标准

Tab. 6 Assessment criteria for F-IBI in the Xiliao River Basin

\begin{tabular}{ccccc}
\hline & 健康 & 亚健康 & 一般 & 较差 \\
\hline $95 \%$ 分位数分值范围 & $>95.72$ & $77.66 \sim 95.72$ & $59.59 \sim 77.66$ & $41.53 \sim 59.59$ \\
\hline
\end{tabular}

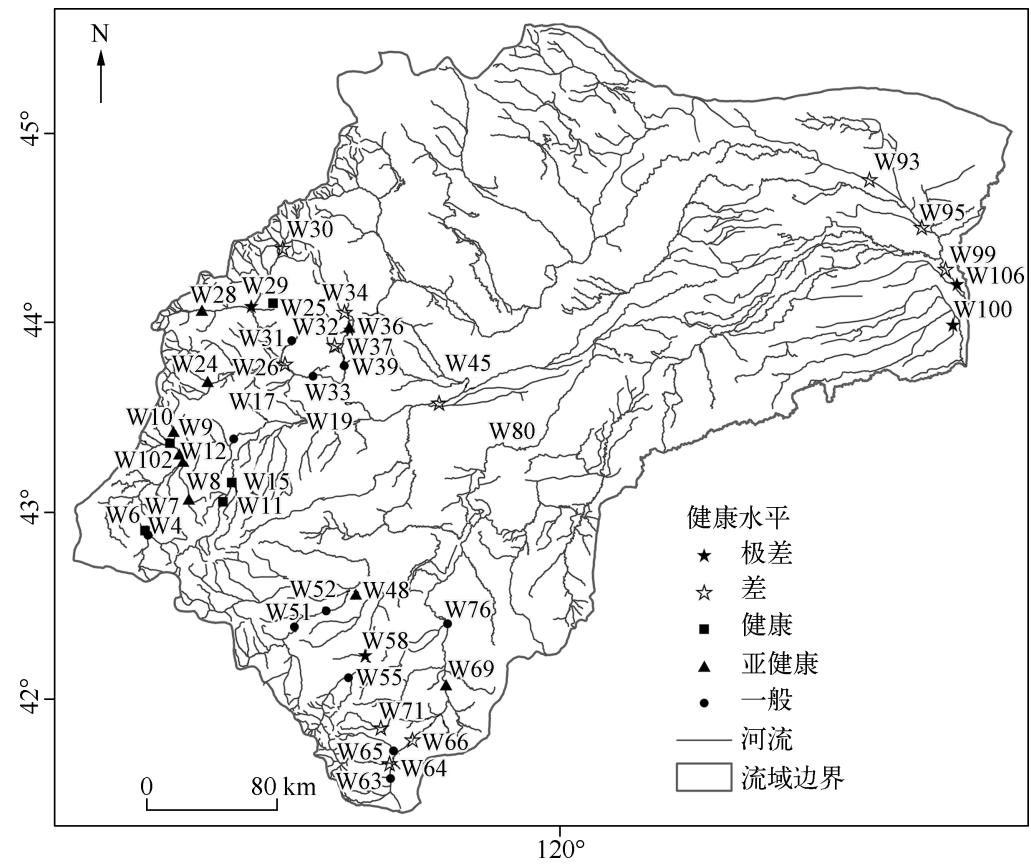

图 3 西辽河流域 F-IBI 评价结果

Fig. 3 F-IBI assessment results in the Xiliao River Basin

\section{3 重要环境变量篮选及其保护限值计算}

分析 F-IBI 值与环境因子的相关关系, 以反映水化学、物理生境和采样点周边土地利用类型对河流健康 的影响程度. 采用 Spearman 相关性分析 IBI 值与环境因子之间的相关性. 结果表明: IBI 与水化学变量中的 $\operatorname{Cond}(P=0.002) 、 \operatorname{Alk}(P=0.003)$ 呈极显著负相关, 与 $\mathrm{NH}_{3}-\mathrm{N}(P=0.035)$ 呈显著负相关; 与物理生境变量中 的坡降 $(P<0.001)$ 呈极显著正相关, 与泥沙比例 $(P=0.038)$ 呈显著负相关; 与土地利用方式中的草地比例 $(P=0.006)$ 呈极显著正相关 (表 7$)$.

西辽河流域 F-IBI 与 Cond 拟合曲线的拐点为 $531 \mu \mathrm{S} / \mathrm{cm}$, 与 $\mathrm{NH}_{3}-\mathrm{N}$ 拟合曲线的拐点为 $0.55 \mathrm{mg} / \mathrm{L}$ 和 $1.35 \mathrm{mg} / \mathrm{L}$, 与 Alk 拟合曲线的拐点为 $4.4 \mathrm{mmol} / \mathrm{L}$, 与坡降拟合曲线的拐点为 $10.4 \%$, 与泥沙比例拟合曲线 的拐点为 $47.2 \%$, 与草地比例拟合曲线的拐点为 $37.0 \%$ (图 4). 经独立样本 $t$ 检验发现 Cond、Alk、泥沙比 
例、草地比例的拐点两侧 F-IBI 得分差异显著, 其 $P$ 值依次为 $0.002 、 0.043 、 0.044$ 和 $0.009 . \mathrm{NH}_{3}-\mathrm{N}$ 的保护限 值 $(0.55 \mathrm{mg} / \mathrm{L})$ 有意义 $(P=0.026) ; \mathrm{NH}_{3}-\mathrm{N}$ 浓度 $(1.35 \mathrm{mg} / \mathrm{L})$ 无意义 $(P=0.19>0.05)$. 坡降的独立样本 $t$ 检验 $P$ 值为 0.801 , 大于 0.05 , 差异不显著.

表 7 西辽河流域 F-IBI 与环境因子之间的相关性系数

Tab. 7 Correlation coefficients between F-IBI and environmental factors in the Xiliao River Basin

\begin{tabular}{cccccc}
\hline 环境因子 & 相关系数 & 环境因子 & 相关系数 & 环境因子 & 相关系数 \\
\hline 水温 & -0.040 & $\mathrm{PO}_{4}^{3-}$ & -0.200 & 小卵石比例 & 0.295 \\
$\mathrm{DO}$ & -0.010 & $\mathrm{TP}$ & -0.110 & 砂砾比例 & 0.296 \\
$\mathrm{pH}$ & -0.010 & $\mathrm{THD}$ & -0.280 & 泥沙比例 & $-0.313^{*}$ \\
$\mathrm{Cond}$ & $-0.460^{* *}$ & $\mathrm{Alk}$ & $-0.440^{* *}$ & 未利用地比例 & -0.274 \\
$\mathrm{Tur}$ & -0.110 & $\mathrm{COD}_{\mathrm{Mn}}$ & -0.210 & 水域比例 & -0.279 \\
$\mathrm{SS}$ & -0.180 & 坡降 & $0.529^{* *}$ & 林地比例 & 0.230 \\
$\mathrm{NH}_{3}-\mathrm{N}$ & $-0.320^{*}$ & 蜿蜒度 & -0.217 & 建设用地比例 & -0.199 \\
$\mathrm{NO}_{3}^{-}$ & 0.290 & 巨砾比例 & 0.193 & 耕地比例 & -0.192 \\
$\mathrm{TN}^{-\mathrm{N}}$ & 0.120 & 找卵石比例 & 0.227 & 草地比例 & $0.405^{* *}$ \\
\hline
\end{tabular}

*表示 $P<0.05 ; * *$ 表示 $P<0.01$.
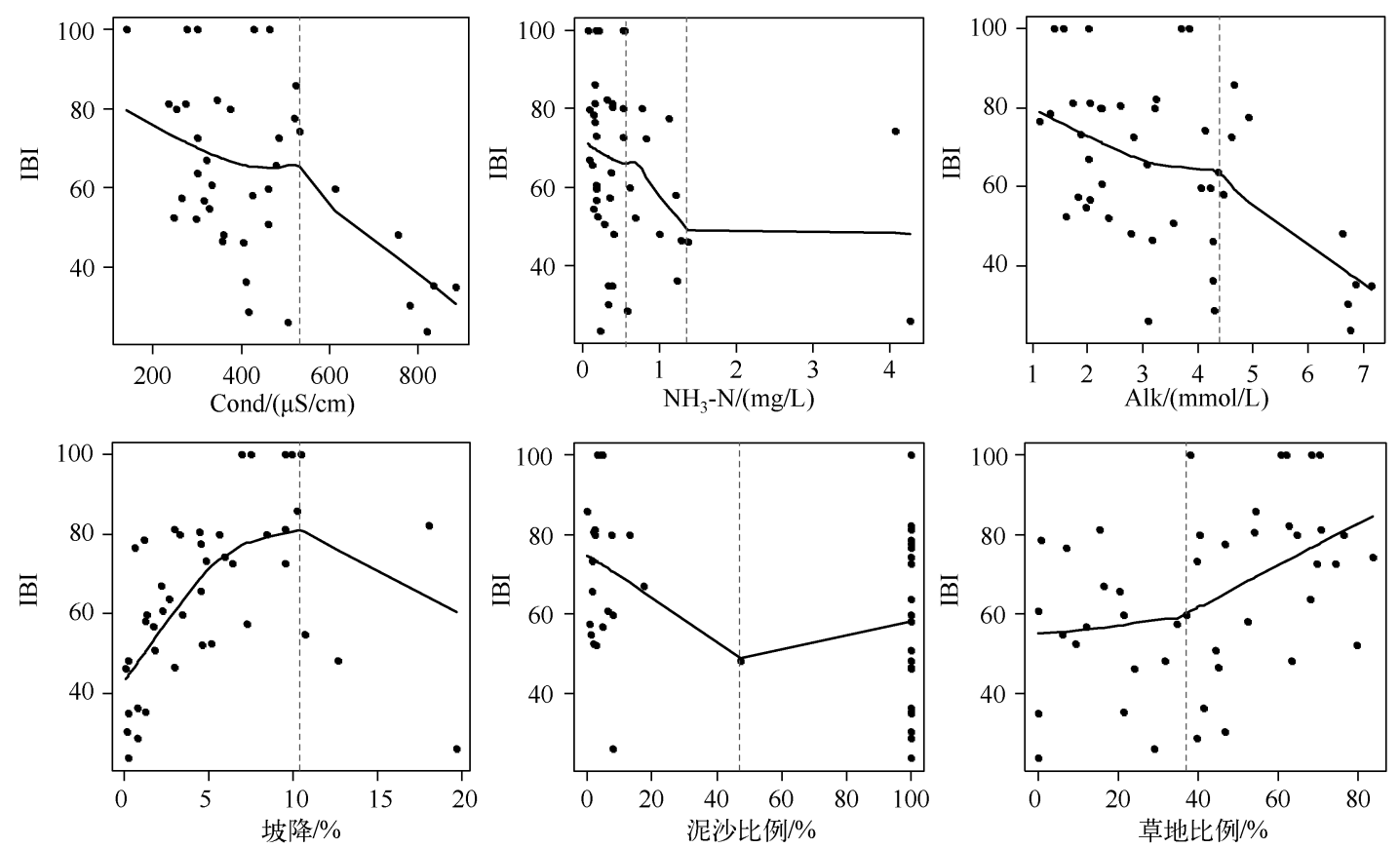

图 4 西辽河流域与 IBI 显著相关环境因子的 LOWESS 曲线及保护限值(垂直虚线代表环境保护限值)

Fig. 4 The LOWESS curves and protection limits of environmental factors that significantly associated with IBI in the Xiliao River Basin(vertical dashed line means the protection limit values of environmental factors)

将对西辽河流域 F-IBI 有重要影响的环境因子做相关性分析, 结果表明: Cond 与 Alk 具有较高的相关性 $(r=0.870)$, 其它环境因子间的相关性较低, 相关系数均未超过 0.5 (图 5). 


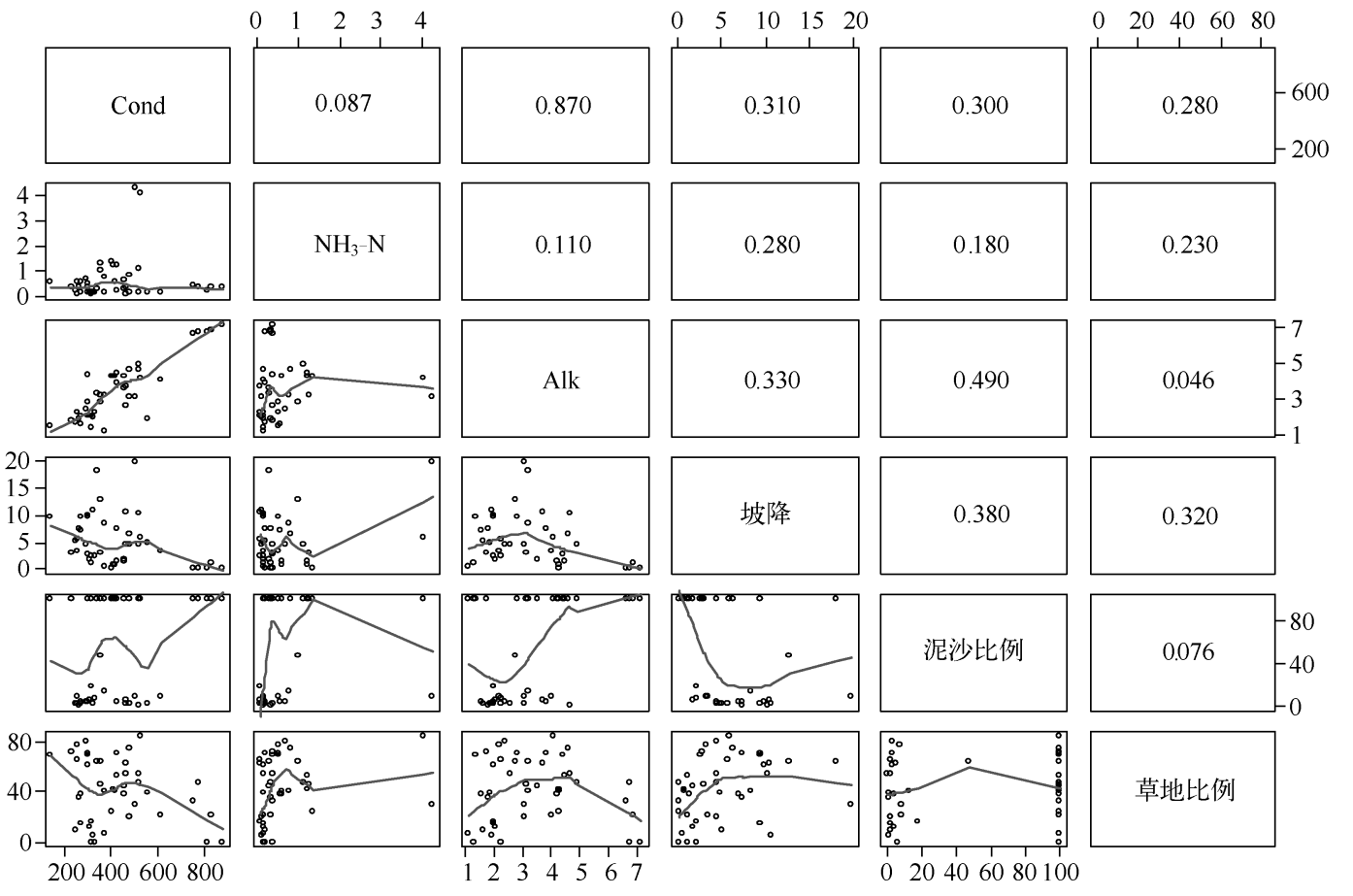

图 5 西辽河流域环境因子间的相关性分析

Fig. 5 Correlation coefficients of environmental factors in the Xiliao River Basin

\section{3 讨论}

\section{1 关于健康标准的划分}

对于确定 F-IBI 核心参数的健康评价标准, 不同学者所采取的标准稍有不同 ${ }^{[1,3,25-26]}$, 这会造成最终的评 价结果有所差异. 一般来讲,参照点 IBI 值的 $25 \%$ 分位数常被作为健康河流样点评价标准,该标准的前提是 参照点选取较为容易且几乎不存在人为干扰因素. 在参照点选取较为困难的情况下,有学者提出 ${ }^{[3,25]}$ 以所有 样点 IBI 值的 $95 \%$ 分位数作为健康评价标准. 此外还有学者依据研究流域本身的特征, 提出以参照点 $50 \%$ 分位数作为健康评价标准, 以 $5 \%$ 分位数作为差等级评价标准, 置于两标准之间的作为亚健康评价标 准 ${ }^{[25-26]}$. 因此,应以所选择的评价标准能客观反映出研究流域整体及各个样点的健康状况为宜. 本研究以参 考点 F-IBI 值的 $95 \%$ 作为健康样点评价标准, 对于小于该标准的进行 4 等分, 该评价结果所反映出的西辽河 流域不同区域健康状况及整体健康状况与高欣等 ${ }^{[16]}$ 利用大型底栖动物生物完整性指数评价的结果类似. 本 研究认为采用参考点 F-IBI 值的 $95 \%$ 作为健康评价标准的依据适合该流域.

\section{2 西辽河环境特征分析及对 F-IBI 的影响}

西辽河流域是我国北方典型的农业区与牧业区交汇过渡地带,其所流经区域为我国内蒙古高原向辽河 平原过渡地带. 该流域上游以山地、林地和草场为主, 中下游以农田和城镇用地为主, 并伴有水域和荒芜用 地 ${ }^{[27-28]}$. 根据国家《地表水环境质量标准》, 西辽河流域水体 $\mathrm{COD}_{\mathrm{Mn}} 、 \mathrm{NH}_{3}-\mathrm{N} 、 \mathrm{TN}$ 和 $\mathrm{TP}$ 等参数变化幅度均较 大. 该区域上游海拔较高, 人类活动相对较少, 水质较为清洁, 中下游区域受农田灌溉、放牧、城市生活污水 及企业废水排放的影响,水质较差. 西辽河的物理生境特征以坡降变化和底质粒径组成的变化最为明显. 坡 降变化剧烈的原因与该流域海拔变化幅度有关,较大的坡降有助于提高水体的氧含量 ${ }^{[29]}$. 底质粒径组成变 化大说明该流域河流的生境差异较大,底质粒径与区域自然地理地貌、气候特征及人类活动有关.

关于水化学对 F-IBI 影响的探讨:第一,通常认为河流中的 Cond 高低受自然和人为两方面因素影 
响 ${ }^{[30]}$, 不同区域 Cond 背景值差异较大. Kimmel 等 ${ }^{[31]}$ 以美国宾夕法尼亚州一条受煤矿废水影响的溪流为对 象, 提出保护该河流鱼类群落结构的 Cond 保护限值为 $3000 \sim 3500 \mu \mathrm{S} / \mathrm{cm}$. 本课题组在太子河流域的研究发 现, 保护溪流中大型底栖动物群落结构完整的 Cond 保护限值为 $277.1 \mu \mathrm{S} / \mathrm{cm}$ (未发表). 本研究发现西辽河 流域基于鱼类群落的 Cond 保护限值则为 $531 \mu \mathrm{S} / \mathrm{cm}$. 造成上述研究结果差异的原因可能与流域环境本底值 以及研究的生物类群不同有关. Kimmel 等 ${ }^{[31]}$ 的研究中 Cond 保护限值较高与水体长期受到工矿废水影响有 直接关系, 在这种长期压力条件下, 水生生物对环境干扰的耐受性提高, 生物群落结构也逐渐趋于稳定, 较 高的环境背景压力下研究得到的保护限值有可能会高于其他低环境干扰压力区域的. 西辽河流域处于高原 向平原过渡地带, 该流域大部分区域受到降水、灌溉等因素影响, 河道内水量不足, 而在放牧造成草地退化 的同时, 流域坡度差异导致水体对河岸侵蚀加剧, 地表风化严重, 最终造成水体 Cond 背景值整体偏高, 其中 Alk 对 Cond 的贡献较大 (图 5). 另外, 有研究发现 ${ }^{[31-32]}$ 大型底栖动物对环境的干扰比鱼类更为敏感, 不同的 研究对象会使环境因子保护限值结果存在差异. 第二, Alk 会对鱼类群落产生影响. 黎道丰等 ${ }^{[33]}$ 发现高盐碱 度会降低鱼类种类数量并导致鱼类生长缓慢. 本研究也发现相似的结果, 碱度增加会降低 F-IBI 评价得分. 第三, 本研究发现 $\mathrm{NH}_{3}-\mathrm{N}$ 的有效保护限值为 $0.55 \mathrm{mg} / \mathrm{L}$, 处于 II III 类水质之间, 这与国家《地表水环境质 量标准》中渔业水质要求相一致. W102 点位的 $\mathrm{NH}_{3}-\mathrm{N}$ 浓度达到 $4.07 \mathrm{mg} / \mathrm{L}$, 但 F-IBI 得分为 74.3 , 同时该点 位草地比例较高 $(84 \%)$, 河岸带生境质量较好. 一方面较好的河岸带生境条件有利于对外源 $\mathrm{NH}_{3}-\mathrm{N}$ 输人起 到缓冲作用 ${ }^{[18]}$, 另一方面较好的生境条件有利于维持较好的鱼类群落结构 ${ }^{[34]}$.

关于物理因素对 F-IBI 影响的探讨: 西辽河区域处于内蒙古高原向辽河平原的过渡区域, 坡降变化较 大. 同时受干旱和人为干扰等因素的影响, 草场退化和荒漠化情况不容乐观, 因此确定上述环境因子的保护 限值具有重要意义. 坡降指河流水面单位距离的落差, 其可以直接影响水体的流速, 对于底质泥沙含量比较 高的区域, 水流速度较大导致水体的浊度升高, 不利于光合作用的正常进行, 导致藻类产氧量降低, 同时泥 沙可堵塞鱼类鳃丝, 对其呼吸造成影响 ${ }^{[35]}$; 有研究表明 ${ }^{[36-37]}$ 泥沙对水体中的 $\mathrm{NH}_{3}-\mathrm{N}$ 和重金属等有毒物质有 吸附作用, 并随着水流带到下游区域, 对区域水质的改善具有一定的作用, 但会加重下游区域的污染情况; 草地对于提高河流生境质量, 防止水土流失和土地沙漠化有着重要作用, 同时可以缓解其它环境因子的负 面影响 ${ }^{[18]}$. 因此, 在区域管理中, 恢复和保持草地比例, 防止土地荒漠化和水土流失, 控制河流底质中的泥沙 比例,最终提高 F-IBI 状况具有重要意义.

\section{4 参考文献}

[ 1 ] Aparicio E, Carmona-Catot G, Moyle PB et al. Development and evaluation of a fish-based index to assess biological integrity of Mediterranean streams. Aquatic Conservation: Marine and Freshwater Ecosystems, 2011, 21(4) : 324-337.

[ 2 ] Karr JR. Assessment of biotic integrity using fish communities. Fisheries, 1981, 6(6) : 21-27.

[ 3 ] Barbour MT, Gerritsen J, Snyder BD et al. Rapid Bio-assessment Protocols for use in wadeable streams and rivers: Periphyton, benthic macroinvertebrates, and Fish: 2nd ed. Washington DC: 841-B-99-002. USA: U. S. Environmental Protection Agency, EPA, 1999.

[ 4 ] Kane DD, Gordon SI, Munawar M et al. The Planktonic Index of Biotic Integrity(P-IBI) : An approach for assessing lake ecosystem health. Ecological Indicators, 2009, 9(6): 1234-1247.

[ 5 ] EC(European Communities). Directive 2000/60/EC of the European Parliament and of the Council of 23 October 2000 establishing a framework for Community action in the field of water policy. Official Journal of the European Communities, 2000, L $327: 1-72$.

[6] 黄 艺, 舒中亚. 基于浮游细菌生物完整性指数的河流生态系统健康评价一一以滇池流域为例. 环境科学, 2013, 34 (8) : 3010-3018.

[ 7 ] 殷旭旺, 张 远, 渠晓东等. 浑河水系着生藻类的群落结构与生物完整性. 应用生态学报, 2011, 22 (10): $2732-2740$.

[8] Lunde KB, Resh VH. Development and validation of a macroinvertebrate index of biotic integrity (IBI) for assessing urban impacts to Northern California freshwater wetlands. Environmental Monitoring and Assessment, 2012, 184 (6): 3653-3674. 
[ 9 ] 郑海涛. 怒江中上游鱼类生物完整性评价 [ 学位论文].武汉:华中农业大学,2006.

[10］渠晓东, 刘志刚, 张 远. 标准化方法篮选参照点构建大型底栖动物生物完整性指数. 生态学报, 2012,32 (15): 4661-4672.

[11] 蔡 琨, 张 杰, 徐兆安等. 应用底栖动物完整性指数评价太湖生态健康. 湖泊科学, 2014, 26 (1): 74-82. DOI 10. $18307 / 2014.0109$.

[12］陈宏文, 张 萌, 刘足根等. 赣江流域淡水生态系统完整性与健康状态的鱼类 F-IBI 值评价. 长江流域资源与环境, $2011,20(9)$ : 1098-1107.

[13] 陈 桥, 徐东烔, 张 翔等. 太湖流域平原水网区底栖动物完整性健康评价. 环境科学研究, 2013,26 (12): $1301-1308$

[14] 黄亮亮, 吴志强,蒋 科等. 东苕溪鱼类生物完整性评价河流健康体系的构建与应用. 中国环境科学, 2013,33(7): 1280-1289.

[15] 朱 迪,陈 锋,杨 志等. 基于鱼类生物完整性指数的水源地评价. 水生态学杂志,2012,33(2): 1-5.

[16] 高 欣,张 远,丁 森等. 西辽河大型底栖动物生物完整性评价及同环境因子关系的探讨. 中国环境科学学会学 术年会论文集(2014),2014:3153-3163.

[17］吴东浩,于海燕, 吴海燕等. 基于大型底栖无脊椎动物确定河流营养盐浓度阈值一以西苔溪上游流域为例. 应用 生态学报,2010,21(2): 438-488.

[18] Mantyka-Pringle CS, Martin TG, Moffatt DB. Understanding and predicting the combined effects of climate change and land-use change on freshwater macroinvertebrates and fish. Journal of Applied Ecology, 2014, 51(3) : 572-581.

[19］孙小舟,封志明,杨艳昭等. 西辽河流域近 60 年来气候变化趋势分析. 干早区资源与环境,2009,23(9):62-66.

[20］国家环境保护总局《水和废水监测分析方法》编委会. 水和废水监测分析方法:第 4 版. 北京: 中国环境科学出版 社,2002.

[21］裴雪娇,牛翠娟,高 欣等. 应用鱼类完整性评价体系评价辽河流域健康. 生态学报,2010,30(21): 5736-5746.

[22] 宋智刚,王 伟,姜志强等. 应用 F-IBI 对太子河流域水生态健康评价的初步研究. 大连海洋大学学报, 2010,25 (6) : 480-487.

[23 ] Celeste PK, Nadanovsky P. Income and oral health relationship in Brazil: is there a threshold? Community Dent Oral Epidemiol, 2009, 37 (4) : 285-293.

[24] 解玉浩. 东北地区淡水鱼类. 沈阳:辽宁科学技术出版社,2007:29-439.

[25] 池仕运,竺维佳,施练东等. 应用底栖动物完整性指数评价水源地水库溪流健康状态. 水生态学杂志, 2012,33(2)： $16-25$.

[26] Astin L. Developing biological indicators from diverse data: the potomac basic-wide index of benthic integrity (B-IBI). Ecological Indicators, 2007, 7(4) : 895-908

[27] 孟 伟,张 远,郑炳辉. 辽河流域水生态分区研究. 环境科学学报,2007,27(6): 911-918.

[28］王金龙. 辽河流域水生态功能三级区水生态服务功能评价 [学位论文]. 沈阳: 辽宁大学,2013.

[29] 刘 婷, 㚞贵盛, 阳 辉. 潇河流域水质污染的空间变化特征. 人民黄河,2014,36(3): 58-60.

[30］李姗迟,郑雄波,高全洲等. 东江流域河水电导率形成机制. 中山大学学报,2013,52 (1): 142-146.

[31] Kimmel WG, Argent DG. Stream fish community responses to a gradient of specific conductance. Water, Air, and Soil Pollution, 2010, 206(1/2/3/4) : 49-56.

[32] Kennedy AJ, Cherry DS, Currie RJ. Field and laboratory assessment of a coal processing effluent in the Leading Creek Watershed, Meigs County, Ohio. Archives of Environmental Contamination and Toxicology, 2003, 44: 324-331.

[33] 黎道丰,蔡庆华. 不同盐碱度水体的鱼类区系结构及主要经济鱼类生长的比较. 水生生物学报, 2000,24 (5): 493-501.

[34] Pinto BCT, Araujo FG, Hughes RM. Effects of landscape and riparian condition on a fish index of biotic integrity in a large southeastern Brazil river. Hydrobiologia, 2006, 556 (1) : 69-83.

[35］白音包力㚖,陈兴茹. 水库排沙对下游河流鱼类影响研究进展. 泥沙研究,2012, (1) : 74-80.

[36] 王而立,王嗣淇,王 亮. 西辽河流域沙土对氨氮的吸附行为研究. 环境科学与技术,2011,34(6G) : 102-106.

[37] 易雨君. 长江水沙环境变化对鱼类的影响及栖息地数值模拟 [学位论文]. 北京: 清华大学,2008. 